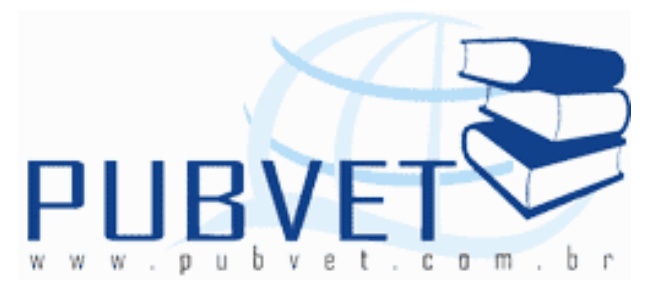

PUBVET, Publicações em Medicina Veterinária e Zootecnia.

\title{
Criptosporidiose em ruminantes: revisão
}

Solange de Oliveira ${ }^{1,2}$; Maurício Orlando Wilmsen ${ }^{1}$; Fernanda Rosalinski-Moraes ${ }^{3}$

1 Graduandos em Medicina Veterinária, Pontifícia Universidade Católica do Paraná, PUCPR-Campus Toledo

${ }^{2}$ Bolsista Fundação Araucária, Programa Universidade sem Fronteiras

3 Professor Adjunto, Universidade Federal de Uberlândia, UFU. fermoraes@famev.ufu.br

\section{Resumo}

A criptosporidiose é uma das causas mais comuns de diarréia e atraso no crescimento em bezerros, cordeiros e cabritos de até um mês de idade. Além dos prejuízos na pecuária, a infecção por Cryptosporidium parvum também é uma importante zoonose, e os bovinos são considerados os principais reservatórios da infecção humana nos países desenvolvidos. Apesar da importância desta enfermidade, seu diagnóstico não é rotina na maior parte das propriedades no Brasil. Isso se deve ao pequeno tamanho do oocisto de $C$. parvum, que dificulta a visualização em exames coproparasitológicos de rotina. Este manuscrito tem por objetivo revisar os principais aspectos da criptosporidiose em ruminantes. 
OLIVEIRA, S., WILMSEN, M.O. e ROSALINSKI-MORAES, F. Criptosporidiose em ruminantes: revisão. PUBVET, Londrina, V. 6, N. 8, Ed. 195, Art. 1309, 2012.

\title{
Cryptosporidiosis in ruminants: review
}

\begin{abstract}
Cryptosporidiosis is one of the main causes of diarrhea and low growth rate in calves, lambs and kids during the first month of age. Besides of the losses in livestock, the infection by Cryptosporidium parvum is also an important zoonosis, and cattle are considered major reservoirs of human infection in developed countries. Despite the importance of this disease, its diagnosis is not routine in most farms in Brazil. This is due to the small size of the oocysts of C. parvum, which hinders the view in routine coproparasitologic examinations. This manuscript aims to review the main aspects of cryptosporidiosis in ruminants.
\end{abstract}

\section{INTRODUÇÃO}

A criptosporidiose é considerada uma doença nova, emergente e de distribuição cosmopolita (COSENDEY et al., 2008). É também uma das principais causas de diarréia em bezerros de 4 a 30 dias idade (ORTOLANI \& SOARES, 2003). Além dos bovinos, a infecção por Cryptosporidium também é associada à diarréia em cordeiros, cabritos, leitões, potros, perus e filhotes de cães e gatos. Em alguns hospedeiros, como o homem, o protozoário é capaz de se replicar no epitélio renal, vesical e respiratório, além das células intestinais, especialmente em pacientes imunodeprimidos, tais como portadores do vírus HIV, crianças e gestantes (URQUHART et al., 1998; De GRAAF et al., 1999a,b).Por isto, a doença é responsável por grandes prejuízos em saúde pública, interferindo na qualidade de vida das pessoas infectadas (MONIS \& THOMPSON, 2003).

A grande quantidade de oocistos eliminados nas fezes dos animais de produção gera uma contaminação ambiental importante, o que possibilita o contágio humano através de água e alimentos contaminados, uma vez que não há nenhuma forma de remoção eficaz dos oocistos esporulados (JOACHIM, 
OLIVEIRA, S., WILMSEN, M.O. e ROSALINSKI-MORAES, F. Criptosporidiose em ruminantes: revisão. PUBVET, Londrina, V. 6, N. 8, Ed. 195, Art. 1309, 2012.

2004). Além disso, a perda econômica pela diarréia e atraso de crescimento nos rebanhos é considerável. Devido a esses fatores o Cryptosporidium tem sido um dos parasitas de interesse médico veterinário mais estudados na atualidade (De GRAAF et al., 1999a; COSENDEY 2008).

\section{SISTEMÁTICA}

Segundo LEVINE et al.(1980), o gênero Cryptosporidium apresenta a seguinte classificação sistemática:

Reino: Protista

Sub-Reino: Protozoa

Phylum: Apicomplexa

Classe: $\quad$ Sporozoea

Sub-Classe: Coccidea

Ordem: Eucoccidea

Sub-Ordem: Eimeriina

Família: Cryptosporidiidae

Gênero: Cryptosporidium

Os avanços da biologia molecular permitiram a identificação de 18 espécies e mais de 40 genótipos de Cryptosporidium (XIAO \& RYAN, 2008). Dentre estas espécies, C. parvum (TYZZER, 1912), C. andersoni (LINDSAY et al., 2000) e C. bovis (FAYER et al., 2005) são aquelas mais frequentemente associadas à doença clínica em bovinos. Destas espécies, C. parvum é a mais estudada, por ser capaz de infectar muitas espécies de mamíferos (XIAO \& FAYER, 2008). Além do potencial zoonótico, C. parvum é também considerada a espécie mais patogênica para bovinos, ovinos e caprinos (XIAO, 2010).

Cryptosporidium andersoni apresenta oocistos morfologicamente semelhantes aos de $C$. muris, razão pela qual boa parte dos artigos revisados das décadas de 80 e 90 trazerem a segunda espécie como de importância em 
OLIVEIRA, S., WILMSEN, M.O. e ROSALINSKI-MORAES, F. Criptosporidiose em ruminantes: revisão. PUBVET, Londrina, V. 6, N. 8, Ed. 195, Art. 1309, 2012.

bezerros desmamados e jovens adultos. Apesar da morfologia semelhante, C. andersoni não foi capaz de infectar camundongos, mesmo imunocomprometidos. Além disso, a análise dos CDNA da unidade 18S, do ITSI e do gene da HSP-70 demonstraram seqüências diferentes daquelas registradas para o C. muris, isolado de camundongos (LINDSAY et al., 2000). Além de bovinos, C. andersoni já foi isolado de ovinos, camelos, gerbis, Mastomys natalensis e perdizes (XIAO \& FAYER, 2008).

Até ser descrito como C. bovis por FAYER et al. (2005), esta espécie era conhecida como Cryptosporidium genótipo B-bovino. Seus oocistos são morfologicamente idênticos aos de $C$. parvum, mas não são infectantes para roedores e são de baixa infectividade para ovinos.

Também já foram isolados de bovinos Cryptosporidium felis; C. hominis; C. suis, além do genótipo cervídeo. No entanto, para nenhuma destas espécies os bovinos são considerados os hospedeiros preferenciais do protozoário (XIAO \& FAYER, 2008).

\section{CICLO BIOLÓGICO}

O ciclo biológico de Cryptosporidium é semelhante ao de outros coccídeos gastrintestinais (FIGURA 1). O hospedeiro se infecta através da ingestão de oocistos esporulados liberados com fezes do animal doente ou portador. Após ingestão, os esporozoítos são liberados do oocisto e invadem a periferia rugosa das microvilosidades dos enterócitos. Esta localização na célula é conhecida como intracitoplasmática mas extracelular.

Uma vez instalados na célula intestinal, ocorre rapidamente a evolução para esquizontes e merócitos, com quatro ou oito merozoítos no seu interior. Com a ruptura do merócito (e da membrana celular do enterócito), os merozoítos são liberados para atingir novas células. Este tipo de reprodução assexuada, na qual se diferenciam os merozoítos a partir dos esquizontes, é chamada esquizogonia (URQUHART et al., 1998; FAYER, 2008). 
OLIVEIRA, S., WILMSEN, M.O. e ROSALINSKI-MORAES, F. Criptosporidiose em ruminantes: revisão. PUBVET, Londrina, V. 6, N. 8, Ed. 195, Art. 1309, 2012.

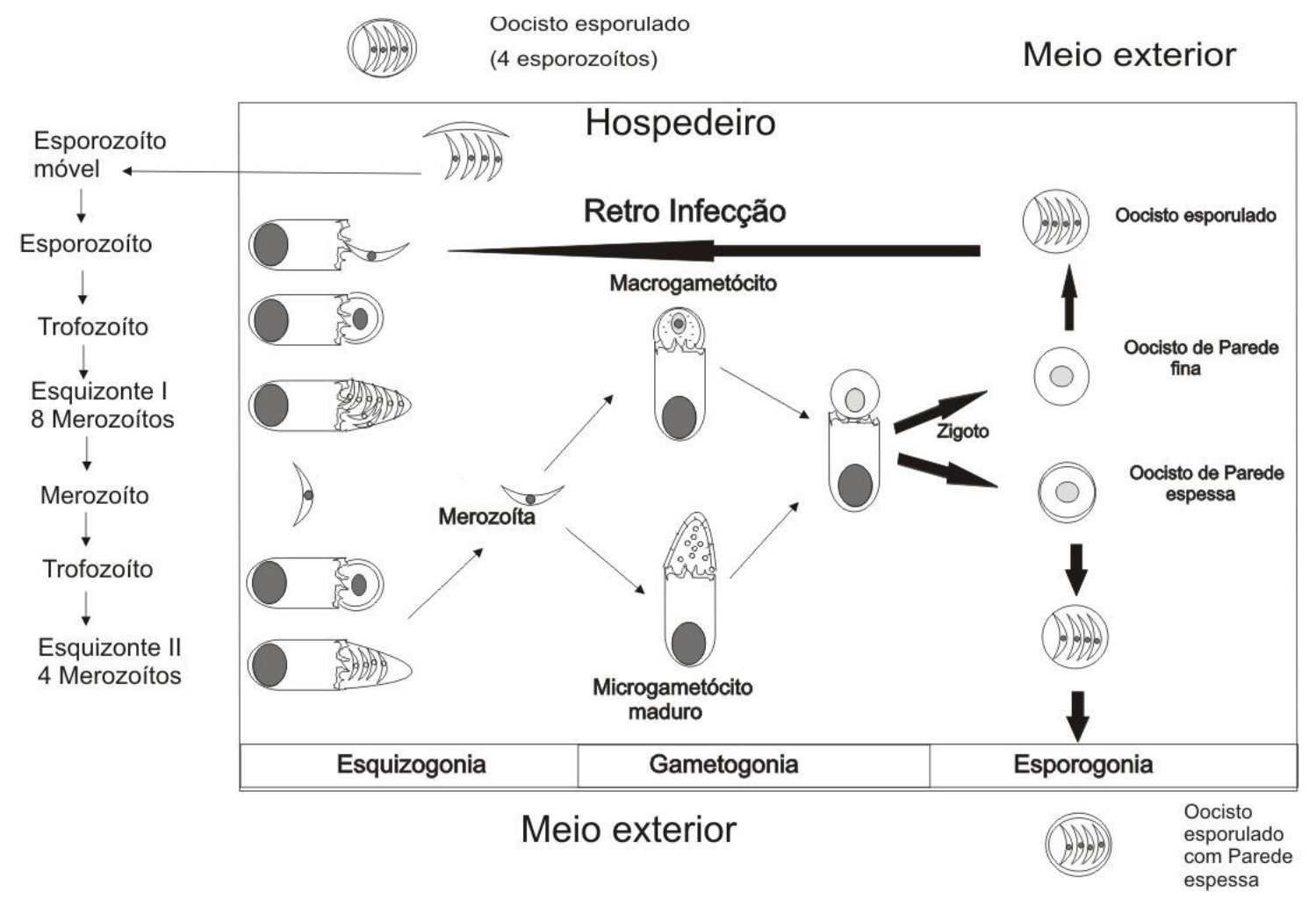

FIGURA 1 - Diagrama esquemático do ciclo biológico de Cryptosporidium sp. Adaptado de Ortolani, 1988.

Após duas gerações de esquizogonia, ocorre a reprodução sexuada ou gametogonia. Nesta fase, os merozoítos de segunda geração se diferenciam em macro e microgametócito após entrada no enterócito. Depois de maduros, os microgametas são liberados. Da fusão dos núcleos do macro e do microgameta origina-se a célula ovo ou zigoto (URQUHART et al., 1998).

A célula ovo diferencia-se em oocisto. Assim como para Sarcocystis spp., ocorre esporulação do oocisto ainda no interior do indvíduo. Ao esporular, cada oocisto apresenta quatro esporozoítos. Estes oocistos podem ser de dois tipos: de parede fina e de parede espessa. Os oocistos de parede fina representam cerca de $20 \%$ do total de oocistos e parecem romper no interior do mesmo indivíduo, causando auto-infecção interna. Os $80 \%$ restantes são oocistos de parede espessa, liberados no meio ambiente (ORTOLANI, 1988; BOWMAN, 2010). 
OLIVEIRA, S., WILMSEN, M.O. e ROSALINSKI-MORAES, F. Criptosporidiose em ruminantes: revisão. PUBVET, Londrina, V. 6, N. 8, Ed. 195, Art. 1309, 2012.

O período pré-patente descrito para bovinos é de 2 a 9 dias. A infecção patente pode durar de 2 a 14 dias, dependendo da idade, imunidade, nutrição do hospedeiro e da quantidade de oocistos ingerida (ORTOLANI, 1988).

\section{PATOGENIA}

São descritos dois quadros clínicos para a infecção em bezerros: um de enterite aguda, com grave diarréia, desidratação e perda de peso, acometendo principalmente crias em lactação, e outro assintomático, associado à diminuição na produção de leite, comum em animais desmamados e jovens adultos (ORTOLANI, 1988). O primeiro quadro normalmente é associado à infecção por Cryptosporidium parvum, parasita de células intestinais; o segundo é relacionado à infecção do abomaso por $C$. andersoni em animais adultos, C. bovis ou genótipo cervídeo em bezerros desmamados (LINDSAY et al., 2000; SANTIN et al., 2004; XIAO \& FAYER, 2008).

Cryptosporidium parvum é também considerado um dos patógenos mais importantes em cordeiros e cabritos, pois causa enterites graves que estão associadas com diarréia e morte em animais experimental e naturalmente infectados (TZIPORI et al., 1983; GOMA et al., 2007). Outros agentes causadores de diarréia importantes nesta fase são, respectivamente, a Escherichia coli, o rotavírus, o Clostridium perfringens, e a Salmonella spp. Entretanto, Eimeria spp. passa a ser o agente mais importante após a quarta semana de vida, tanto para ovinos quanto para caprinos (De GRAAF et al., 1999a). Além da diarréia, também são associadas à criptosporidiose de pequenos ruminantes os sinais de apatia, anorexia e dores abdominais (CONSENDEY et al., 2008).

No trato gastrintestinal de animais acometidos por Cryptosporidium parvum, é observado parasitismo nas bordas das microvilosidades dos intestinos delgado e grosso (CONSENDEY et al., 2008). A diarréia observada pode ser decorrente de dois mecanismos. Um deles é a má absorção, uma vez que os esquizontes e gamontes se desenvolvem em um invólucro parasitário 
OLIVEIRA, S., WILMSEN, M.O. e ROSALINSKI-MORAES, F. Criptosporidiose em ruminantes: revisão. PUBVET, Londrina, V. 6, N. 8, Ed. 195, Art. 1309, 2012.

derivado das microvilosidades intestinais. Com a ruptura do invólucro para liberação dos estádios intermediários, ocorre atrofia, entumescimento e fusão das microvilosidades (URQUHART et al., 1998). Além das lesões causadas, TZIPORI et al. (1983) verificaram que o nível da enzima lactase encontra-se diminuído nos animais parasitados. Com isso, a lactose láctea não é digerida satisfatoriamente. Como o leite constitui uma importante fonte de nutrientes para bezerros na faixa etária de maior ocorrência de criptosporidiose, há uma grande quantidade de lactose na dieta. $O$ acúmulo de lactose na luz intestinal promove a atração de fluidos para o intestino. Este fluxo osmótico caracteriza o segundo mecanismo de diarréia. Em indivíduos imunocompetentes, a diarréia é considerada auto-limitante (YARLETT et al., 2007).

\section{EPIDEMIOLOGIA}

\section{a) Morbidade e prevalência da criptosporidiose em rebanhos}

A diarréia causada por Cryptosporidium parvum em bezerros de quatro a trinta dias de vida é associada a uma morbidade alta, de 9 a 85\% (ORTOLANI, 1988; ORTOLANI \& SOARES, 2003; SANTÍN et al., 2004;). A mortalidade normalmente é baixa, a não ser associada a outras infecções intestinais, como coronavirose, rotavirose e salmonelose (ORTOLANI, 1988; ORTOLANI \& SOARES, 2003).

Além de C. parvum, outras espécies de Cryptosporidium podem acometer bezerros leiteiros em lactação. SANTÍn et al. (2004) encontraram $9 \%$ dos bezerros positivos para Cryptosporidium spp., oriundos de 15 fazendas de sete estados da costa norte-americana, estavam infectados com C. bovis, $5 \% \mathrm{com}$ o genótipo cervídeo e $1 \%$ com $C$. andersoni. Os mesmos autores encontraram $85 \%$ dos bezerros positivos para C. parvum, porém nenhum bezerro com mais de dois meses de idade foi positivo para este parasito.

Cryptosporidium andersoni é associado a infecções brandas em bovinos de todas as idades, especialmente em jovens adultos (LINDSAY et al. 2000; XIAO 
OLIVEIRA, S., WILMSEN, M.O. e ROSALINSKI-MORAES, F. Criptosporidiose em ruminantes: revisão. PUBVET, Londrina, V. 6, N. 8, Ed. 195, Art. 1309, 2012.

\& FAYER, 2008). Em bezerros leiteiros desmamados (de três a 11 meses de idade), SANTÍn et al. (2004) encontraram de 9 a 66\% de prevalência para Cryptosporidium spp. Destes animais, 55\% dos animais apresentaram C. bovis; $31 \%$ genótipo cervídeo; $13 \%$ C. andersoni e $1 \%$ C. parvum. Os mesmos autores observaram que os animais eliminaram predominantemente oocistos de $C$. bovis dos dois aos sete meses de idade, e a proporção de animais eliminando oocistos de $C$. andersoni aumentou conforme a idade.

Em pequenos ruminantes, a criptosporidiose se comporta semelhantemente ao observado em rebanhos bovinos. GOMA et al. (2006) relataram prevalência de $10,1 \%$ a $68,3 \%$ em cordeiros e $11,1 \%$ a $35,2 \%$ em cabritos. De GRAAF et al. (1999a) consideraram o C. parvum como o agente mais importante na diarréia neonatal dos cordeiros, sendo isolado em $65 \%$ dos rebanhos com surtos de diarréia e em média de $45 \%$ dos cordeiros de cada rebanho. No Brasil, CONSENDEY et al. (2008) encontraram prevalência média de 47\% (20 a 80\%) em ovinos da raça Santa Inês de dez propriedades amostradas.

No entanto, nem todos os animais positivos para oocistos de Cryptosporidium em exames coproparasitológicos apresentam diarréia clínica. ORTOLANI (1988) demonstraram 38,0\% dos bezerros de 0 a 60 dias apresentavam diarréia por Cryptosporidium e $11,5 \%$ eram portadores assintomáticos. Em ovinos, $17 \%$ dos animais avaliados por CONSENDEY et al. (2008) eliminaram oocistos de Cryptosporidium, porém não apresentavam sinais clínicos compatíveis com a infecção. Quando se utilizam métodos de detecção acurados, pode-se observar que animais adultos assintomáticos eliminam pequenas quantidades de oocistos esporadicamente (De GRAAF et al.,1999a).

Como na maior parte das doenças transmitidas pela via oro-fecal, a maior ou menor incidência da criptosporidiose clínica está diretamente ligada ao manejo sanitário do rebanho. Assim, o estado de portador assintomático é maior em propriedades com melhor manejo sanitário. Em propriedades com piores condições higiênico-sanitárias, com manejo nutricional precário e 
OLIVEIRA, S., WILMSEN, M.O. e ROSALINSKI-MORAES, F. Criptosporidiose em ruminantes: revisão. PUBVET, Londrina, V. 6, N. 8, Ed. 195, Art. 1309, 2012.

inadequado fornecimento de colostro, ocorre um maior número de casos de diarréia por criptosporidiose (BOMFIM \& LOPEZ, 1995; De GRAAF et al. 1999a; ORTOLANI \& SOARES, 2003; CONSENDEY et al. 2008).

Sistemas intensivos de produção, que resultam em maior presença de umidade nas instalações e em maior contato dos animais com suas fezes também predispõem à ocorrência e à severidade da infecção por Cryptosporidium (CONSENDEY et al., 2008). No entanto, OLIVEIRA-FILHO et al. (2007) encontraram 30\% de bezerros nelore com diarréia e $10 \%$ dos bezerros assintomáticos positivos para Cryptosporidium, indicando que esta doença também pode ser comum em bezerros de corte criados extensivamente.

\section{b) Fontes de contaminação}

A transmissão do Cryptosporidium ocorre classicamente via oro-fecal. O contato animal-animal, a água e os alimentos contaminados são as principais fontes de infecção. Animais doentes e portadores assintomáticos funcionam como reservatórios e fonte de contaminação do meio ambiente (De GRAAF et al.,1999a).

Animais jovens doentes são a maior fonte de contaminação. Bezerros recém-nascidos infectados eliminam de $10^{6}$ a $10^{7}$ oocistos por grama de fezes (oopg) (De GRAAF et al.,1999a). Os animais assintomáticos eliminam menores quantidades de oocistos nas fezes (ORTOLANI \& SOARES, 2003).

Como os oocistos já estão esporulados no momento da eliminação, a infecção pode se espalhar rapidamente de animal para animal quando os bezerros/cordeiros estão alojados em pequenas instalações, e/ou em superpopulação. As fêmeas adultas também podem contaminar o úbere com fezes ao se deitar nas instalações, possibilitando o contágio das crias por ocasião do aleitamento (De GRAAF et al.,1999a).

Em pequenos ruminantes, já foi observado um aumento peripuerperal na eliminação de oocistos de Cryptosporidium (ORTEGA-MORA et al, 1999). 
OLIVEIRA, S., WILMSEN, M.O. e ROSALINSKI-MORAES, F. Criptosporidiose em ruminantes: revisão. PUBVET, Londrina, V. 6, N. 8, Ed. 195, Art. 1309, 2012.

Embora a eliminação de oocistos tenha variado de apenas 20 a 440 oopg, este pequeno número de oocistos pode ser responsável pela infecção dos cordeiros logo após o nascimento. Como os partos tendem a se concentrar em uma determinada época do ano, as ovelhas adultas podem ser responsáveis pela manutenção da infecção de um ano para outro (De GRAAF et al.,1999a).

Quanto à introdução da doença em uma propriedade, outras fontes de contaminação devem ser apuradas. Como as diferentes espécies de Cryptosporidium podem apresentar outros hospedeiros além dos ruminantes (XIAO \& FAYER, 2008), deve-se considerar a possibilidade de outras espécies animais contaminarem o meio para infectar os animais de produção (CONSEDEY et al. 2008).

\section{c) Viabilidade do estádio infectante}

Os oocistos de C. parvum apresentam grande resistência no meio. FAYER et al. (1998) submeteram estes oocistos a várias temperaturas $(-10,-5,0,5$, $10,15,20,30$ e $35^{\circ} \mathrm{C}$ ), retirando uma alíquota a cada $1,2,4,8,12,16,20$ ou 24 semanas. Em cada alíquota a viabilidade era acessada através da inoculação em ratos e da mensuração da amilopectina (polissacarídeo de reserva em coccídeos). Oocistos mantidos a $-10^{\circ} \mathrm{C}$ foram infectantes até a primeira semana de estocagem; a $-8{ }^{\circ} \mathrm{C}$, até oito semanas. Oocistos deixados de 0 a $20^{\circ} \mathrm{C}$ foram infectantes até 24 semanas após a estocagem. Isto indica que os oocistos de $C$. parvum devem persistir no meio por mais de 24 semanas à temperatura ambiente, em condições de umidade (FAYER, 2008).

Como a cloração da água não é capaz de inativar o oocisto, CONSENDEY et al. (2008) não observaram diferença significativa na ocorrência de criptosporidiose em ovinos oriundos de propriedades com e sem tratamento de água. De nove diferentes desinfetantes testados por CAMPBELL et al. (1982), apenas o formaldeído a $10 \%$ e a amônia a 5 e a $10 \%$ foram capazes de eliminar o oocisto. 
OLIVEIRA, S., WILMSEN, M.O. e ROSALINSKI-MORAES, F. Criptosporidiose em ruminantes: revisão. PUBVET, Londrina, V. 6, N. 8, Ed. 195, Art. 1309, 2012.

\section{d) Criptosporidiose como zoonose}

Em humanos, a doença é relacionada à falta de saneamento básico e à contaminação da água de bebida. A falta de saneamento básico é a maior responsável pela maior prevalência da criptosporidiose em países em desenvolvimento. Em países desenvolvidos, a maior preocupação é o estabelecimento de métodos de monitoramento da contaminação de água potável, que pode estar contaminada por esgoto ou por dejetos animais (De GRAAF et al.,1999b).

Estudos moleculares têm demonstrado que a infecção humana por C. parvum e a importância da contaminação da água de bebida por dejetos animais é mais importante em países europeus. Nos Estados Unidos, Canadá, Austrália, Japão e países em desenvolvimento, a infecção humana por C. hominis é mais comum, e a transmissão é principalmente antroponótica (XIAO \& FAYER, 2008; XIAO 2010). Nesses países, a infecção zoonótica por C.parvum parece ser mais importante em crianças de áreas rurais e em pessoas com risco ocupacional (XIAO et al. 2004; XIAO \& FAYER, 2008). Portanto, veterinários e tratadores teriam maior possibilidade de contágio (MORGAN et al., 1997).

\section{DIAGNÓSTICO}

Os oocistos de Cryptosporidium sp. são de difícil observação em exames coproparasitológicos de rotina devido ao seu diminuto diâmetro (TABELA 1). Este é um dos principais motivos responsáveis pela falta de diagnóstico da criptosporidiose em infecções clínicas a campo. Segundo BOWMANN (2010), o melhor método de pesquisa destes oocistos é a flutuação em solução saturada de sacarose $(d=1,33)$. Quando esta técnica é utilizada, os oocistos podem apresentar um halo hialino rosado. Este halo ocorre devido aberração

cromática em objetivas de qualidade regular. Os oocistos tendem a permanecer em um plano logo inferior à lamínula. Sendo assim, sugere-se que 
OLIVEIRA, S., WILMSEN, M.O. e ROSALINSKI-MORAES, F. Criptosporidiose em ruminantes: revisão. PUBVET, Londrina, V. 6, N. 8, Ed. 195, Art. 1309, 2012.

seja feita a leitura de um exame de rotina micrometrando entre camadas mais profundas e mais superficiais do material examinado. Estruturas que se assemelhem a oocistos devem ser observadas no aumento de 400 vezes.

TABELA 1 - Valores aproximados das medidas do oocisto esporulado de Cryptosporidium sp. encontrados por vários autores.

\begin{tabular}{lllll}
\hline Hospedeiro & Espécie & \multicolumn{2}{c}{ Valores $(\mu \mathrm{m})$} & \multirow{2}{*}{ Autores } \\
\cline { 3 - 4 } & & Diâmetro equatorial & Diâmetro polar \\
\hline Camundongo & C. parvum & $4.0-4.5$ & $3.0-3.3$ & TYZZER, 1912 \\
Bovino & C. muris (sin. & $7,4(6.6-7.9)$ & $5,6(5,3-6,5)$ & UPTON \& CURRENT, \\
& C. andersoni) & & & 1985 \\
Bovino & C. parvum & $5,0(4.5-5.4)$ & $4,5(4,2-5,0)$ & UPTON \& CURRENT, \\
& & & & 1985 \\
Bovino & C. bovis & $4,89(4.76-5.35)$ & $(4,17-4,76)$ & FAYER et al. 2005 \\
Bovino & C. andersoni & $6.0-8.1$ & $5.0-6.5$ & LYNDSAY et al. 2000
\end{tabular}

Para facilitar a pesquisa de oocistos de Cryptosporidium, é sugerido o uso de microscópio de contraste de fases e de métodos de coloração. Os métodos de coloração mais utilizados para este fim são: azul de metileno, giemsa, Kinyon modificado; PAS; PAS modificado; tricromio; iodo; mentamina; ZiehlNieelsen (ORTOLANI, 1988; URQUHART et al., 1998; BOWMANN, 2010). Segundo ORTOLANI (1988), o método de Ziehl-Nieeslen é a coloração de escolha, pois possibilita uma melhor diferenciação entre oocistos de Cryptosporidium e leveduras.

Embora as provas biológicas estejam caindo em desuso, outra alternativa de diagnóstico é a inoculação de material suspeito em animais de laboratório, com posterior pesquisa em exame histopatológico (ORTOLANI, 1988; FAYER et al., 1998). Neste caso, destaca-se o uso de camundongos neonatos que usualmente eliminam grandes quantidades de oocistos nas fezes cerca de cinco a seis dias após infecção. O material para histopatologia pode ser fixado em solução de formol a $10 \%$ ou líquido de Bouin e corado com H\&E ou com 
OLIVEIRA, S., WILMSEN, M.O. e ROSALINSKI-MORAES, F. Criptosporidiose em ruminantes: revisão. PUBVET, Londrina, V. 6, N. 8, Ed. 195, Art. 1309, 2012.

ácido periódico de Schift. O exame histológico também pode ser utilizado como diagnóstico post mortem em bovinos (ORTOLANI, 1988). O mesmo autor ainda cita o decalque de mucosa como alternativa de diagnóstico da criptosporidiose em bovinos após até 24 a 36 horas de morte.

As técnicas de imunodiagnóstico e parasitologia molecular também são ferramentas úteis para o diagnóstico da criptosporidiose humana e animal. Dentre os testes de imunodiagnóstico, são citados a imunofluorescência indireta (ORTOLANI, 1988); imunofluorescência direta a partir de esfregaço fecal (SANTIN et al., 2004) e o ELISA para pesquisa de coproantígeno (BOWMAN, 2010).

Nas últimas décadas numerosas técnicas de biologia molecular foram desenvolvidas para detectar e diferenciar as diferentes espécies, genótipos e subtipos de Cryptosporidium. Essas ferramentas são utilizadas em estudos epidemiológicos em áreas endêmicas, bem como para compreender o potencial zoonótico das espécies/genótipos e o papel dos diferentes hospedeiros na ecoepidemiologia da doença (XIAO, 2010). As técnicas de biologia molecular auxiliam o diagnóstico da criptosporidiose por permitir a identificação do parasita logo no período pós-infecção, não dependendo da resposta imune do hospedeiro, e por serem específicas, diminuindo o risco de reações cruzadas. MORGAN et al. (1997) provaram não haver replicação de DNA fecal, do hospedeiro, ou de outros parasitas (Giardia duodenalis, Tritrichomonas foetus) quando trabalharam com primer específico para $C$. parvum através da técnica de PCR. ROCHELLE et al. (1999) também não detectaram a replicação de DNA de $C$. muris e $C$. baileyi ao trabalharem com primers específicos para C. parvum. Isto indica a alta especificidade do teste.

A sensibilidade e especificidade da PCR tem elevado a sua utilização para detectar Cryptosporidium em amostras clínicas e ambientais. WEBSTER et al. (1996) conseguiram ampliar o DNA de C. parvum mesmo na quantidade de 5 oocistos por $\mathrm{ml}$ de fezes diluídas (80 a 90 oocistos por grama de fezes OoPG), através da técnica de PCR. A mesma acurácia só foi atingida em coprologia com o mínimo de 4.000 OoPG, utilizando a técnica de flutuação em 
OLIVEIRA, S., WILMSEN, M.O. e ROSALINSKI-MORAES, F. Criptosporidiose em ruminantes: revisão. PUBVET, Londrina, V. 6, N. 8, Ed. 195, Art. 1309, 2012.

solução de sacarose e coloração com auramine-fenol ou imunofluorescência. Esta alta sensibilidade também permite o isolamento de DNA parasitário de água "potável" contaminada com oocistos (ROCHELLE et al., 1999).

\section{TRATAMENTO}

Apesar da extensa seleção de agentes quimioterápicos ou imunoterapia, não há nenhum tratamento curativo para criptosporidiose totalmente eficaz e disponível comercialmente. (ARMSON et al. 2003; HEIGES et al., 2006). A localização característica do Cryptosporidium no interior da célula pode ser um dos responsáveis pela não efetividade das drogas coccidiostáticas e coccidicidas normalmente empregadas (BOWMAN, 2010). Entretanto, algumas drogas como o lactato de halofuginone, a paromomicina e o decoquinato têm sido empregados com relativo sucesso em alguns experimentos (TABELA 2).

TABELA 2 - Eficácia de diferentes drogas contra a criptosporidiose em ruminantes.

\begin{tabular}{|c|c|c|c|c|c|}
\hline \multirow[b]{2}{*}{ Droga } & \multirow[b]{2}{*}{ Espécie } & \multirow{2}{*}{$\begin{array}{c}\text { Dose/kg } \\
\text { de peso } \\
\text { vivo }\end{array}$} & \multirow{2}{*}{$\begin{array}{c}\text { Período de } \\
\text { adminis- } \\
\text { tração }\end{array}$} & \multicolumn{2}{|c|}{ Melhores Resultados } \\
\hline & & & & $\begin{array}{l}\text { Eliminação } \\
\text { de oocistos }\end{array}$ & Diarréia \\
\hline Lactato de halofuginone & Ovino & $500 \mu \mathrm{g}$ & 1-5 dias & Prevenida & Prevenida \\
\hline Lactato de halofuginone & Bovino & $30-500 \mu \mathrm{g}$ & 3-14 dias & Prevenida & Prevenida \\
\hline Paromomicina & Bovino & $25-100 \mathrm{mg}$ & 11 dias & Prevenida & Reduzida \\
\hline Paromomicina & Caprino & $100 \mathrm{mg}$ & 12 dias & Prevenida & Melhorada \\
\hline Decoquinato & Bovino & $2,5-10 \mathrm{mg}$ & 8 semanas & Diminuída & Melhorada \\
\hline Decoquinato & Caprino & $2,5 \mathrm{mg}$ & 21 dias & Diminuída & Prevenida \\
\hline
\end{tabular}

FONTE: revisto por De GRAAF et al. (1999a).

\section{PREVENÇÃo E CONTROLE}

Tendo em vista a dificuldade de diagnóstico da enfermidade a campo, o potencial zoonótico e a carência de medicamentos eficientes para tratamento, 
OLIVEIRA, S., WILMSEN, M.O. e ROSALINSKI-MORAES, F. Criptosporidiose em ruminantes: revisão. PUBVET, Londrina, V. 6, N. 8, Ed. 195, Art. 1309, 2012.

é importante a adoção de medidas de manejo sanitário que minimizem os fatores predisponentes de infeç̧ão e a contaminação ambiental.

Estratégias de controle para a criptosporidiose em ruminantes são semelhantes aos outros coccídeos. Nessas estratégias estão inclusas boas práticas de criação, como separar os animais com diarréia do restante do rebanho, limpeza das instalações antes da introdução dos animais, remoção e eliminação imediata das fezes ou cama úmida e fornecimento adequado de colostro, pode reduzir o número de oocistos excretados pelos animais e aumentar a resistência ao $C$. parvum e a outros enteropatógenos (HARP e GOFF, 1998). É importante também frisar a higienização diária de comedouros e bebedouros, além de medidas que diminuam a umidade nas instalações. CONSENDEY et al. (2008) encontraram menores prevalências de ovinos positivos para Cryptosporidium em propriedades com limpeza diária dos comedouros, dos bebedouros, e com apriscos ripados ou troca regular da cama.

O uso frequente de probióticos também pode minimizar o estabelecimento de infeç̧ões por Cryptosporidium e/ou diminuir o número de oocistos eliminados (OLIVEIRA-SEQUEIRA et al., 2008).

\section{REFERÊNCIAS BIBLIOGRÁFICAS}

1. ARMSON, A.; THOMPSON, R.C.A.; REYNOLDSON, J.A. A review of chemotherapeutic approaches to the treatment of cryptosporidiosis Expert Review of Anti-infective Therapy, v.1, n. 2 , p.297-305. 2003.

2. BOWMAN, Dwight D. Parasitologia Veterinária de Georgis. 9 ed. São Paulo: Saunders-Elsevier, 2010. 432 p.

3. BOMFIM, T.C.B.; LOPES, C.W. Aspectos comparativos dos oocistos de Cryptosporidium (APICOMPLEXA: CRYPTOSPORIDIIDAE), procedente de suínos (Sus scrofa domestica), camundongos (Mus musculus) e ratos (Rattus rattus) coabitando o mesmo local. Revista Brasileira de Parasitologia Veterinária. v.4, n.1, p.29-32. 1995.

4. CAMPBELL, I.; TZIPORI, A.S.; HUTCHISON, G.; ANGUS, K.W. Effect of disinfectants on survival of Cryptosporidium oocysts. The Veterinary Record. v.111, n. 18, p. 414-415. 1982 
5. COSENDEY, R.I.J.; FIUZA, V.R.S.; OLIVEIRA, F.C.R. Importância do manejo na criptosporidiose em criações de ovinos. Revista Brasileira de Parasitologia Veterinária, v.17, supl.1, p. 209-214.2008.

6. De GRAAF, D.C.; VANOPDENBOSCH, E.; ORTEGA-MORA, L.M.; ABASSI, H.; PEETERS, J.E. A review of the importance of cryptosporidiosis in farm animals. International Journal for Parasitology. v.29, p.1269-1287. 1999a.

7. De GRAAF, D.C.; SPANO, F.; PETRY, F.; SAGODIRA, S.; BONNIN, A. Speculation on whether a vaccine against cryptosporidiosis is a reality or fantasy. International Journal for Parasitology. v.29, p.1289-1306. 1999b.

8. FAYER, R. Biology. In: FAYER, R.; XIAO, L. Cryptosporidium and Cryptosporidiosis. 2 ed. Boca Raton, Fl: CRC Press and IWA Publishing, 2008. p. 119-163.

9. FAYER, R.; TROUT, J.M.; JENKINS, M.C. Infectivity of Cryptosporidium parvum oocysts stored in water at environmental temperatures. The Journal of Parasitology. v.84, n.6, p.1165-1169. 1998.

10. FAYER, R.; SANTIN, M.; XIAO, L. Cryptosporidium bovis n. sp. (Apicomplexa: Cryptosporidiidae) in Cattle (Bos taurus) Journal of Parasitology. v. 91, n. 3, p. 624-629. 2005.

11. GOMA, F.Y.; GEURDEN, T.; SIWILA, J.; PHIRI, I.G.K.; GABRIEL, S.; CLAEREBOUT, E.; VERCRUYSSE, J. The prevalence and molecular characterization of Cryptosporidium spp. in small ruminants in Zambia. Small Ruminant Research, v. 72, n. 1, p. 77-80, 2007.

12. HARP, J.A.; GOFF, J.P. Strategies for the control of Cryptosporidium parvum infection in calves. Journal of Dairy Science, v.81, n.1, p. 289-294. 1998.

13. HEIGES, M.; WANG, H.; ROBINSON, E.; AURRECOECHEA, C.; GAO, X.; KALUSKAR, N.;RHODES, P.; WANG, S.; HE, C., SU, Y.; MILLER, J.; KRAEMER, E.; KISSINGER, J.C. CryptoDB: a Cryptosporidium bioinformatics resource update. Nucleic Acids Research, v. 34, 419-422, 2006.

14. JOACHIM, A. Human Cryptosporidiosis: an update with special emphasis on the situation in Europe. Journal of Veterinary Medicine. B, Infectious Diseases and Veterinary Public Health, v. 51, n. 6, p. 251-259, 2004.

15. LEVINE, N.D.; CORLISS, J. O.; COX, F. E. G.; DEROUX, G.; GRAIN, J.; HONIGBERG, B. M.; LEEDALE, G. F.; LOEBLICH, A. R.; LOM, I. J.; LYNN, D.; MERINFELD, E. G.; PAGE, F. C.; POLJANSKY, G.; SPRAGUE, V.; VAVRA, J.;WALLACE, F. G. A Newly Revised Classification of the Protozoa. Journal of Eukaryotic Microbiology, v. 27, p.37-58. 1980.

16. LINDSAY, D. S.; UPTON, S. J.; OWENS, D. S.; MORGAN, U. M.; MEAD, J. R.; BLAGBURN, B.L. Cryptosporidium andersoni n. sp. (Apicomplexa: Cryptosporiidae) from cattle, Bos taurus. Journal of Eukaryotic Microbiology, v.47, p. 91-95. 2000.

17. MONIS, P.T.; THOMPSON, R.C.A. Cryptosporidium and Giardia-zoonoses: fact or fiction? Infectious, Genetic and Evolution: Journal of Molecular Epidemiology and Evolutionary Genetics in Infectious Diseases, v. 3, n. 4, p. 233-244, 2003.

18. MORGAN, U.M.; CONSTANTINE, C.C.; FORBES, D.A.; THOMPSON, R.C.A. Differentiation betwen human and animal isolates of Cryptosporidium parvum using rDNA sequencing and direct PCR analysis. The Journal of Parasitology v.83, n.5, p.825-830. 1997. 
19. OLIVEIRA FILHO, J.P.; SILVA, D.P.G.; PACHECO, M.D.; MASCARINI, L.M.; RIBEIRO, M.G; ALFIERI, A.A.; ALFIERI, A.F.; STIPP, D.T.; BARROS, B.J.P.; BORGES, A.S. Diarréia em bezerros da raça Nelore criados extensivamente: estudo clínico e etiológico. Pesquisa Veterinária Brasileira. v.27, n.10, p.419-424. 2007.

20. OlIVEIRA-SEQUEIRA, T.C.G.; RIBEIRO, C.M.; GOMES, M.I.F.V. Potencial terapêutico dos probióticos nas parasitoses intestinais.Ciência Rural, v.38, n.9, dez, 2008.

21. ORTOLANI, E.L. Padronização da técnica de ZIEHL-NEELSEN para pesquisa de oocistos de Cryptosporidium. Estudo de alguns aspectos epidemiológicos de criptosporidiose em bezerros de rebanhos leiteiros no estado de São Paulo. São Paulo, 1988. Tese (Doutorado em Ciências - Parasitologia). Instituto de Ciências Biomédicas Universidade de São Paulo.

22. ORTOLANI, E.L.; SOARES, P.C. Epidemiological aspects of Cryptosporidiosis in dairy calves. Parasitología latinoamericana, v. 58, n. 3-4, p. 122-127. 2003.

23. ORTEGA-MORA, L.M.; REQUEJO-FERNÁNDEZ, J.A.; PILAR-IZQUIERDO, M.; PEREIRABUENO, J. Role of adult sheep in transmission od infection by Cryptosporidium parvum to lambs: confirmation of periparturient rise. International Journal for Parasitology, v. 29, p. 1261-1268. 1999.

24. ROCHELLE, P.A.; JUTRAS, E.M.; ATWILL, E.R.; De LEON, R.; STEWART, M.H. Polymorphisms in the $\beta$-tubulin gene of Cryptosporidium parvum differentiate between isolates based on animal host but not geographic origin. The Journal of Parasitology. v.85, n.5, p.986-989. 1999.

25. SANTÍN, M.; TROUT, J.M.; XIAO, L.; ZHOU, L.; GREINER, E.; FAYER, R. Prevalence and age-related variation of Cryptosporidium species and genotypes in dairy calves. Veterinary Parasitology, v. 122, p. 103-177. 2004.

26. TYZZER, E. Cryptosporidium parvum (sp. nov.), a coccidium found in the small intestine of the common mouse. Archives of Protistenkd. v.26, p. 394-412. 1912.

27. TZIPORI, S. Cryptosporidiosis in animals and humans. Microbiological Reviews, v.47, n.1, p. 84-96. 1983.

28. UPTON, S.J.; CURRENT, W. L. The Species of Cryptosporidium (Apicomplexa: Cryptosporidiidae) Infecting Mammals. The Journal of Parasitology, v. 71, n. 5, p. 625-629. 1985.

29. URQUHART, G.M.; ARMOUR, J.; DUNCAN, J.L.; DUNN, A.M.; JENNINGS, F.W. Parasitologia Veterinária. 2.ed. Rio de Janeiro: Editora Guanabara Koogan, 1998.

30. WEBSTER, K.A.; SMITH, H.V.; GILES, M.; DAWSON, L.; ROBERTSON, L.J. Detection of Cryptosporidim parvum oocysts in faeces: comparison of conventional coproscopical methods and the polymerase chain reaction. Veterinary Parasitology, v. 61, n. 1-2, p. 5-13. 1996.

31. XIAO, L. Molecular epidemiology of Cryptosporidiosis: an update. Experimental Parasitology, v.124, n. 1, p. 80-89. 2010.

32. XIAO, L.; FAYER, R. Molecular characterisation of species and genotypes of Cryptosporidium and Giardia and assessment of zoonotic transmission. International Journal for Parasitology, v. 38, p. 1239-1255. 2008. 
33. XIAO, L.; FAYER, R.; RYAN, U.; UPTON, S.J. Cryptosporidium taxonomy: recent advances and implications for public health. Clinical Microbiology Reviews, v.17, n.1, p. 7297. 2004.

34. XIAO, L.; RYAN, U.M. Molecular Epidemiology. In: FAYER, R.; XIAO, L. Cryptosporidium and Cryptosporidiosis. 2 ed. Boca Raton, FI: CRC Press and IWA Publishing, 2008. p. 119-163.

35. YARLETT, N. et al. Cryptosporidium parvum spermidine/spermine $\mathrm{N}(1)$ acetyltransferase exhibits different characteristics from the host enzyme. Molecular and Biochemical Parasitology, v.152, n.2, p.170-80, 2007. 